Check for updates

Cite this: RSC Adv., 2018, 8, 3723

Received 20th December 2017 Accepted 10th January 2018

DOI: 10.1039/c7ra13491f

rsc.li/rsc-advances

\section{Green synthesis of a $\mathrm{Cu} / \mathrm{MgO}$ nanocomposite by Cassytha filiformis L. extract and investigation of its catalytic activity in the reduction of methylene blue, congo red and nitro compounds in aqueous media}

\begin{abstract}
Mahmoud Nasrollahzadeh, (D)*ab Zahra Issaabadi ${ }^{a}$ and S. Mohammad Sajadi ${ }^{c d}$
This work reports the green synthesis of a $\mathrm{Cu} / \mathrm{MgO}$ nanocomposite using Cassytha filiformis $\mathrm{L}$. extract as a reducing agent without stabilizers or surfactants. The immobilization of $\mathrm{Cu}$ NPs was confirmed by Fourier transform infrared spectroscopy (FT-IR), X-ray diffraction (XRD), transmission electron microscopy (TEM), field emission scanning electron microscopy (FESEM) and energy dispersive $X$-ray spectroscopy (EDS). The $\mathrm{Cu} / \mathrm{MgO}$ nanocomposite acts as a heterogeneous and recyclable catalyst for the reduction of 4-nitrophenol (4-NP), 2,4-dinitrophenylhydrazine (2,4-DNPH), methylene blue (MB) and congo red $(\mathrm{CR})$ using sodium borohydride in aqueous media at room temperature. The catalyst was recycled multiple times without any significant loss of its catalytic activity.
\end{abstract}

\section{Introduction}

The presence of azo dyes and nitroarene compounds in waste waters is of great concern for researchers. The dyes and nitroarene compounds used in various industries are often highly toxic to aquatic organisms because these are biologically and chemically stable. Therefore, it is arduous to remove them by natural degradation processes., ${ }^{1,2}$ Degradation of the dyes to nondangerous products ${ }^{3-5}$ and also nitroarenes to useful compounds $\mathrm{s}^{6,7}$ are very important reactions. Recently, scientists have introduced a reduction process in the presence of metal nanoparticles (MNPs) with $\mathrm{NaBH}_{4}$ as a reducing agent for the removal of pollutants from water. ${ }^{8-12}$

The MNPs are more active than their particulate metal counterparts due to their properties, small sizes and large surface areas. Among MNPs, copper nanoparticles (Cu NPs) have attained a particular attention because its cheapness and availability compared to other metal nanoparticles. ${ }^{13-15}$ Despite the advantages of $\mathrm{Cu} \mathrm{NPs}$, their agglomeration is inevitable. The synthesis of heterogeneous catalysts is one of the best ways to overcome the agglomeration of MNPs. ${ }^{16-20}$ Recently, various research groups reported the green synthesis of MNPs

\footnotetext{
${ }^{a}$ Department of Chemistry, Faculty of Science, University of Qom, Qom 3716146611, Iran.E-mail: mahmoudnasr81@gmail.com

${ }^{b}$ Center of Environmental Researches, University of Qom, Qom, Iran

${ }^{c}$ Scientific Research Center, Soran University, PO Box 624, Kurdistan Regional Government, Soran, Iraq

${ }^{d}$ Department of Pharmacy, Rwandz Private Technical Institute, Kurdistan Regional Government, Rwandz, Iraq
}

supported on the various supports such as $\mathrm{TiO}_{2},{ }^{21}$ graphene oxide, ${ }^{22} \mathrm{Fe}_{3} \mathrm{O}_{4}{ }^{23}$ bentonite ${ }^{24}$, perlite ${ }^{25}$ and etc. Among heterogeneous catalysts, $\mathrm{MgO}$ has been used widely as an efficient support and catalyst in organic reactions due to good chemical and thermal stability, low cost, high surface area, ease of handling and high catalytic activity reusability. ${ }^{26}$

Nowadays various techniques have been proposed for the green synthesis of metal nanoparticles using plant extracts as biological materials under mild conditions. ${ }^{27-30}$ Plants extract mediated synthesis of NPs can be beneficial for preparing nanometals to control the size, shape and distribution size. The green approach for the synthesis of MNPs by using plants extract are very desirable compared to other physical and chemical methods because their advantages such as use of nontoxic solvents, simple work-up procedure, very mild reaction conditions, cleaner reaction profiles, elimination of toxic and dangerous materials, elimination of high pressure, energy, temperature, cost effectiveness and dangerous materials without using of surfactant, capping agent and or template. ${ }^{31-33}$

Cassytha filiformis L. from the Cassythaceae family is a medicinal plant of tropical region of Asia and America which mainly uses in traditional medicine for treatment of cancer, Fig. 1. Because of the presence of its rich phytochemical content in modern medical research, $C$. filiformis has been investigated to possess a number of biologically active chemical compounds with the therapeutic potential in human health applications. ${ }^{34,35}$ Some of the isolated compounds from the extracts of this plant are aporphine alkaloid, oxo-aporphine alkaloid, cassyformine, filiformine, cathaformine, lignan, actinodophine, and octenine. Previous studies on the plant extract strongly support the 


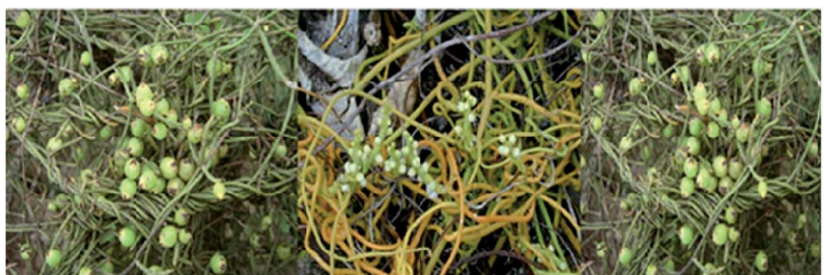

Fig. 1 Image of Cassytha filiformis L. plant.

presence of bioactive phytochemicals such as alkaloids, phenolics, flavonoids, glycosides, resins, proteins, carbohydrates, saponines and tannins. ${ }^{36-39}$ Through this research the aqueous extract of the Cassytha filiformis L. was used as reducing media to biosynthesis of stable nanostructures without application of poisonous chemicals and harsh reaction conditions.

In this work, we reported the preparation of $\mathrm{Cu} / \mathrm{MgO}$ nanocomposite via a new, fast, simple, green, cost effective and ecofriendly process by using Cassytha filiformis L. extract as stabilizing and reducing agent for the reduction of $\mathrm{Cu}^{2+}$ ion to $\mathrm{Cu}^{0}$. Then, the catalytic activity of $\mathrm{Cu} / \mathrm{MgO}$ nanocomposite was investigated against organic dyes such as $\mathrm{CR}, \mathrm{MB}$ and nitro compounds such as 2,4-DNPH and 4-NP using $\mathrm{NaBH}_{4}$ as the source of hydrogen.

\section{Experimental}

\section{Reagents and methods}

All materials with commercial reagent grade were obtained from the Merck and Aldrich companies and used without further purification. FT-IR spectra were recorded on a Nicolet 370 FT/IR spectrometer (Thermo Nicolet, USA) using pressed $\mathrm{KBr}$ pellets. The formation of nanoparticles was recorded by UVvisible spectral analysis on a double-beam spectrophotometer (Hitachi, U-2900). The shape and size of the $\mathrm{Cu} / \mathrm{MgO}$ nanocomposite were identified by transmission electron microscope (TEM) using a Philips EM208 microscope operating at an accelerating voltage of $90 \mathrm{kV}$. Field emission scanning electron microscopy (FE-SEM) was performed on a cam scan MV2300. EDS (energy dispersive X-ray spectroscopy) was utilized for chemical analysis of prepared nanostructures. X-ray diffraction (XRD) mensuration were carried out using a Philips powder diffractometer type PW 1373 goniometer $(\mathrm{Cu} \mathrm{K} \alpha=1.5406 \AA)$. The scanning rate was $2^{\circ} \mathrm{min}^{-1}$ in the $2 \theta$ range from 10 to $90^{\circ}$.

\section{Preparation of Cassytha filiformis L. fruit extract}

$50 \mathrm{~g}$ of dried powder of the plant fruit was added to $250 \mathrm{~mL}$ double distillated water in $500 \mathrm{~mL}$ flask and well mixed. The preparation of extract was using magnetic heating stirrer at $70{ }^{\circ} \mathrm{C}$ for $30 \mathrm{~min}$. The obtained extract was centrifuged in $7000 \mathrm{rpm}$ and filtered then filtrate was kept at refrigerator to use further.

\section{Green synthesis of Cu NPs}

In a $250 \mathrm{~mL}$ conical flask, $10 \mathrm{~mL}$ solution of $\mathrm{CuCl}_{2} \cdot 2 \mathrm{H}_{2} \mathrm{O}(5 \mathrm{mM})$ was mixed with $100 \mathrm{~mL}$ of the aqueous plant extract along with vigorous shaking until gradually changing the color of the mixture from yellow to dark during $5 \mathrm{~min}$ indicating the formation of $\mathrm{Cu}$ NPs (as monitored by UV-vis spectrum). The mixture then filtered and centrifuged at $7000 \mathrm{rpm}$ for $30 \mathrm{~min}$ and obtained precipitation washed with $n$-hexane and absolute ethanol to remove possible impurities, Scheme 1.

\section{Preparation of the $\mathrm{Cu} / \mathrm{MgO}$ nanocomposite using the aqueous} extract of the Cassytha filiformis $\mathrm{L}$.

For green synthesis of $\mathrm{Cu}$ NPs immobilized on $\mathrm{MgO}$ as a support, $25 \mathrm{~mL}$ of $\mathrm{CuCl}_{2} \cdot 2 \mathrm{H}_{2} \mathrm{O}(5 \mathrm{mM})$ was added dropwise

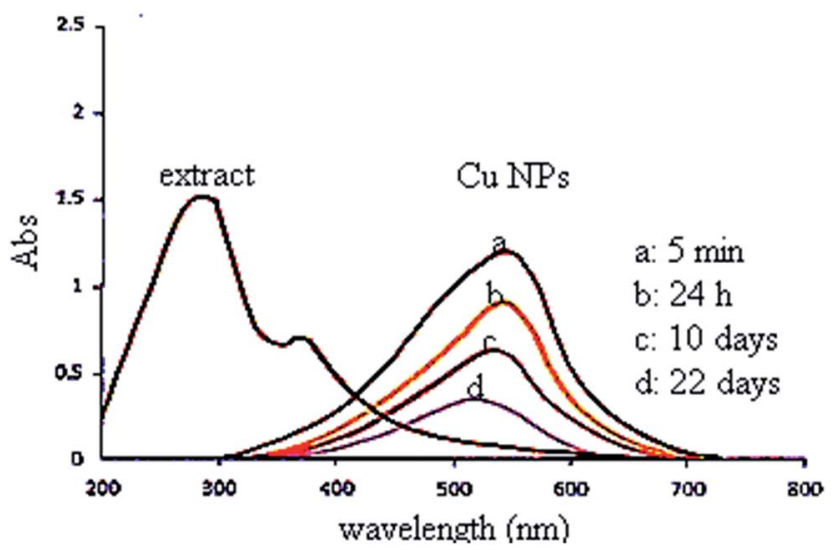

Fig. 2 UV-vis spectra of the plant extract and green synthesized Cu NPs.

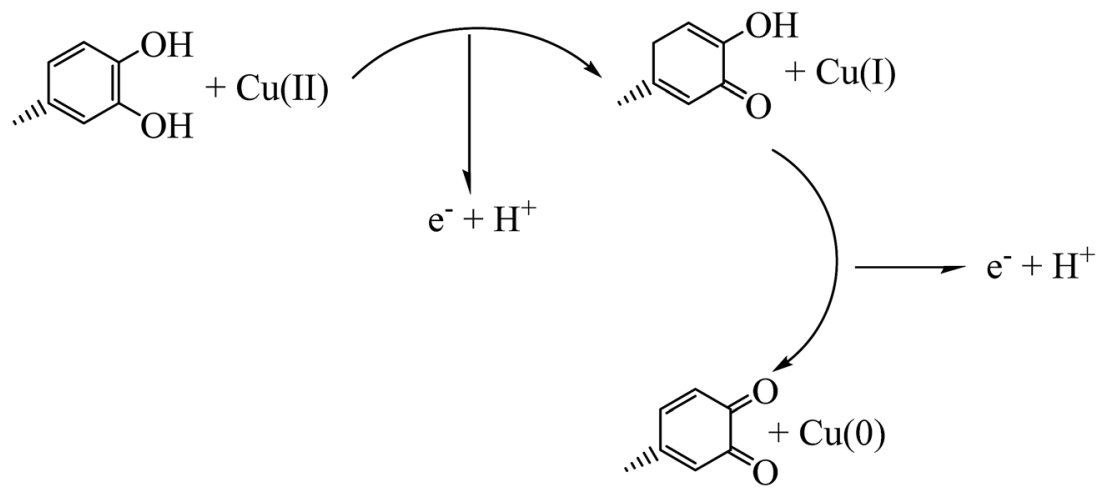

Scheme 1 Proposed mechanism for green synthesis of Cu NPs. 


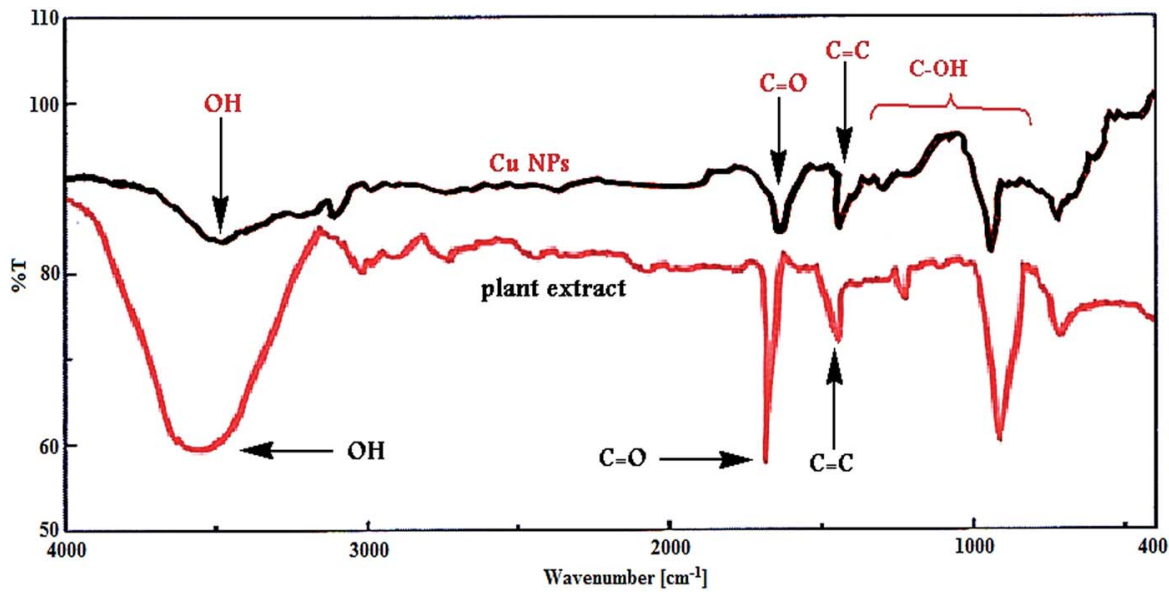

Fig. 3 FT-IR spectra of biosynthesized Cu NPs and plant extract.

to a well-mixed solution of the above extract and $1.0 \mathrm{~g}$ of $\mathrm{MgO}$ with constant stirring at $80{ }^{\circ} \mathrm{C}$ for $4 \mathrm{~h}$. Finally, the prepared $\mathrm{Cu} / \mathrm{MgO}$ nanocomposite was separated by centrifugation, washed several times with distilled water and then dried at $90{ }^{\circ} \mathrm{C}$ for $2 \mathrm{~h}$.

\section{General procedure for the reduction of 4-NP at room} temperature

To evaluate the catalytic activity, a mixture containing $10.0 \mathrm{mg}$ of $\mathrm{Cu} / \mathrm{MgO}$ nanocomposite and $25 \mathrm{~mL}$ of 4-NP aqueous solution
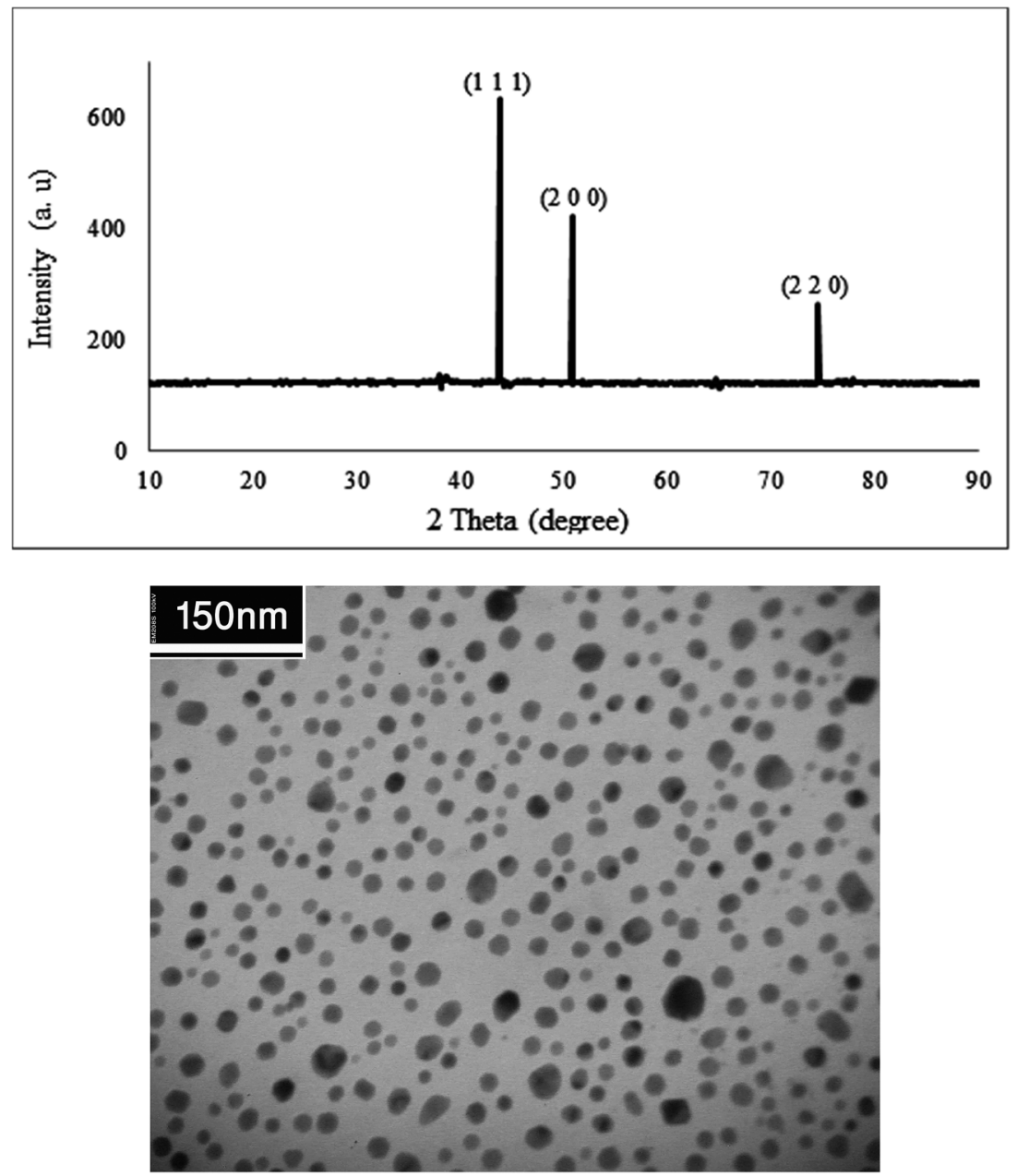

Fig. 4 The XRD pattern and TEM image of biosynthesized Cu NPs. 
(2.5 $\mathrm{mM}$ ) was stirred for $3 \mathrm{~min}$ in a beaker. In the next step, freshly prepared $\mathrm{NaBH}_{4}$ aqueous solution $(0.25 \mathrm{M}, 25 \mathrm{~mL})$ was added and stirred for $5 \mathrm{~min}$ at room temperature. The concentration of 4-NP was determined using a Hitachi, U-2900 spectrophotometer. After completion of the reaction, the catalyst was simply separated by brief centrifugation and washed successively with distilled water, dried and used for successive cycles.

\section{General procedure for the reduction of 2,4-DNPH at room temperature}

In a typical experiment, freshly prepared aqueous $\mathrm{NaBH}_{4}$ solution (7.91 mM, $25 \mathrm{~mL}$ ) was added to an aqueous solution that contained 2,4-DNPH (10.076 mM, $25 \mathrm{~mL})$ and $10.0 \mathrm{mg}$ of the $\mathrm{Cu} / \mathrm{MgO}$ nanocomposite and stirred at room temperature and the reduction process was monitored by recording UV-vis spectra. After completion of the reaction process, the catalyst was filtered, washed with doubly distilled water and then reused.

\section{General procedure for the reduction of $\mathrm{MB}$ and $\mathrm{CR}$ at room} temperature

In a typical reduction protocol, $25 \mathrm{~mL}$ of organic dye solution (MB: $3.1 \times 10^{-5} \mathrm{M}$, CR: $1.44 \times 10^{-5} \mathrm{M}$ ) was mixed with $10.0 \mathrm{mg}$ of the $\mathrm{Cu} / \mathrm{MgO}$ nanocomposite and the mixture was stirred at room temperature. Then a freshly prepared $\mathrm{NaBH}_{4}$ aqueous solution $\left(5.3 \times 10^{-3} \mathrm{M}, 25 \mathrm{~mL}\right)$ was added and mixture was stirred at room temperature. The reaction was monitored using the UV-vis spectroscopy. At the end of the reaction, the catalyst was simply separated from the reaction system by brief centrifugation and washed with doubly distilled water and then dried at $100{ }^{\circ} \mathrm{C}$ for $2 \mathrm{~h}$ for the next cycle.

\section{Results and discussion}

Preparation and characterization of the $\mathrm{Cu} / \mathrm{MgO}$ nanocomposite

In this study, the plant extract was used as a reducing and stabilizing agent for the synthesis of Cu NPs without addition of
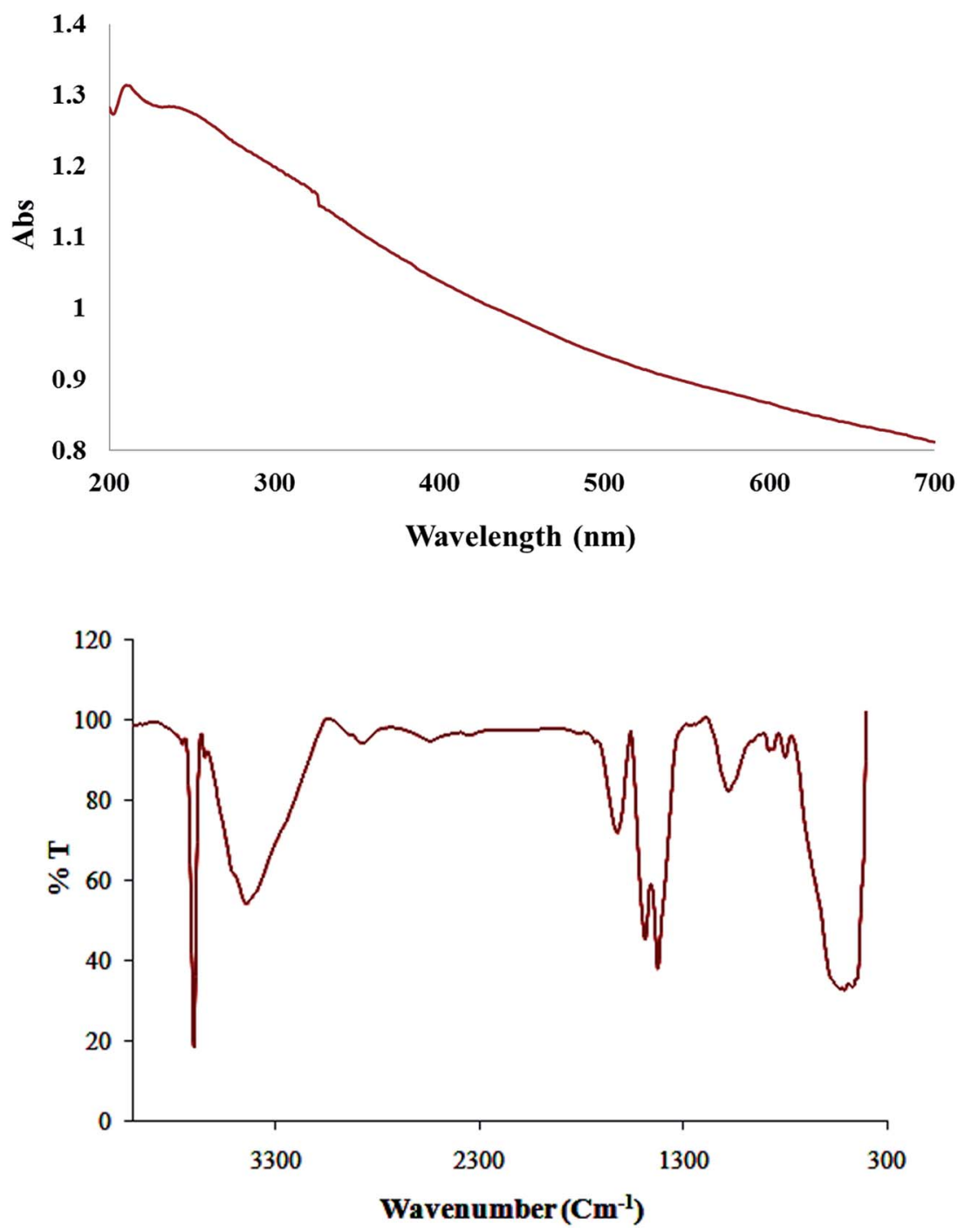

Fig. 5 UV-vis and FT-IR spectra of biosynthesized $\mathrm{Cu} / \mathrm{MgO}$ nanocomposite. 


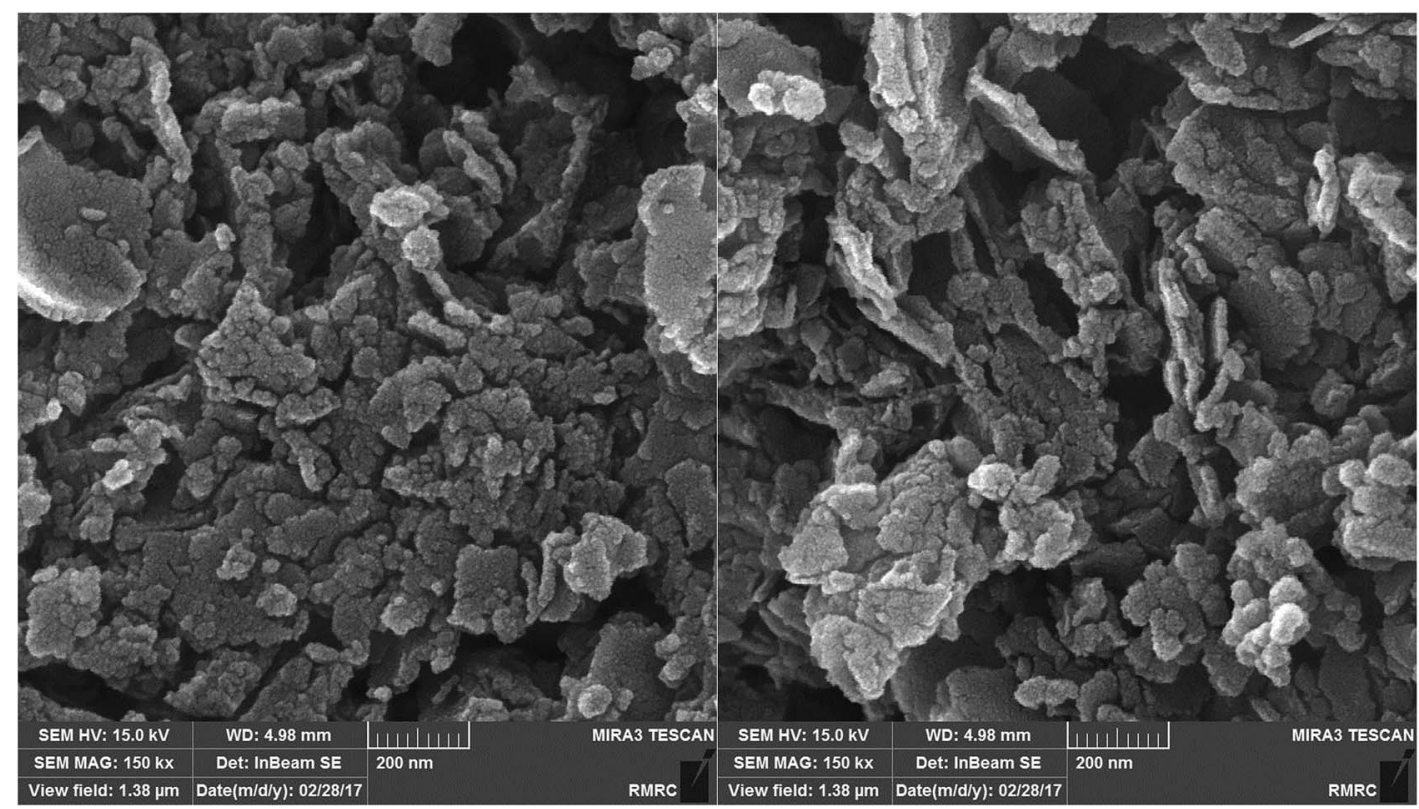

Fig. 6 FESEM images of the $\mathrm{Cu} / \mathrm{MgO}$ nanocomposite.

any other external reducing agent. Moreover, the UV spectrum of extract (Fig. 2) shows bands at $375 \mathrm{~nm}$ (band I) and $288 \mathrm{~nm}$ (band II) assigned to the cinnamoyl and benzoyl systems of phenolics compounds. Therefore, the UV results support the presence of phenolics in plant extract as reported by literatures. ${ }^{36-39}$

The UV-vis spectrum of green synthesized Cu NPs using the plant extract (Fig. 2) showed the significant changes in the absorbance maxima due to surface plasmon resonance. The color of the mixture changed into dark after $5 \mathrm{~min}$ at $555 \mathrm{~nm}$ indicating formation of $\mathrm{Cu}$ NPs as characterized by UV-vis spectrum. The synthesized $\mathrm{Cu}$ NPs by this method are quite stable with no significant variance in the shape, position and symmetry of the absorption peak even after 22 days.

Furthermore, Fig. 3 shows the FT-IR spectrum of Cu NPs and plant extract for comparison in which shows the interaction between $\mathrm{CuCl}_{2} \cdot 2 \mathrm{H}_{2} \mathrm{O}$ and involved sites of phytochemicals to synthesis of Cu NPs (Fig. 3). The peaks at 3500, 1695, 1432, 1300 and $1000 \mathrm{~cm}^{-1}$ represent the $\mathrm{OH}$ functional groups, carbonyl group $(\mathrm{C}=\mathrm{O})$, stretching $\mathrm{C}=\mathrm{C}$ aromatic ring and $\mathrm{C}-\mathrm{OH}$ stretching vibrations, respectively. Phytochemicals could adsorb on the surface of metal nanoparticles, possibly by interaction through $\pi$-electrons interaction in the absence of other strong ligating agents.

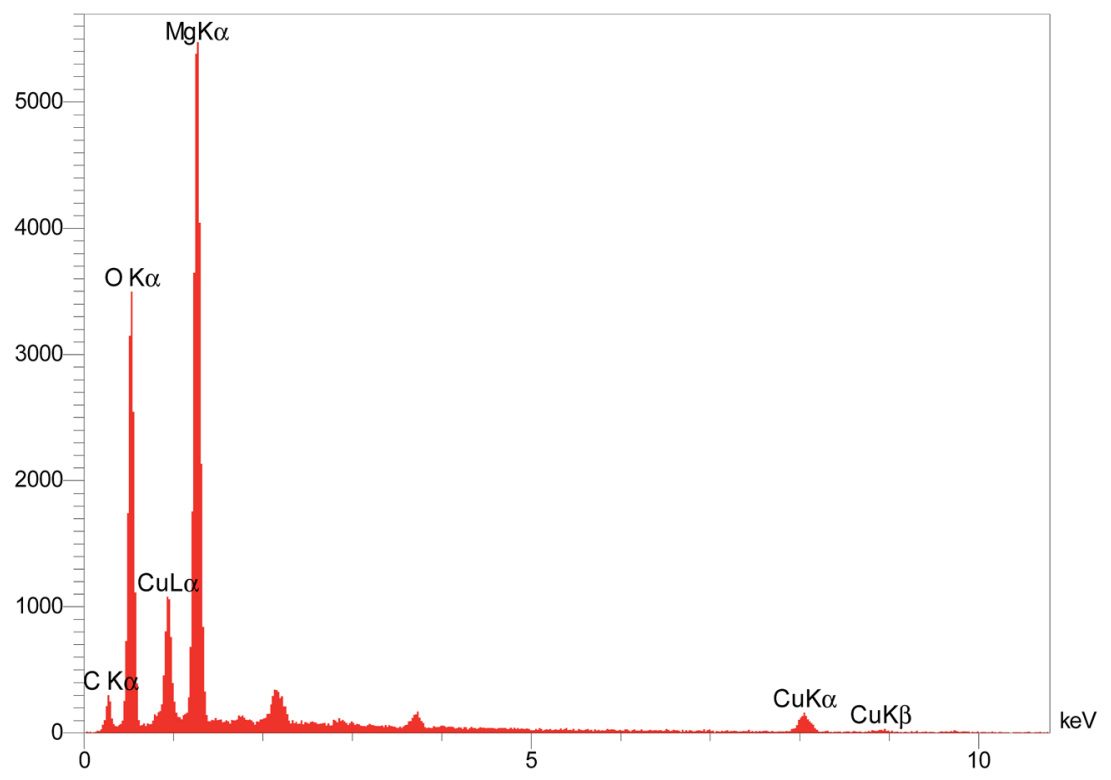

Fig. 7 EDS spectrum of the $\mathrm{Cu} / \mathrm{MgO}$ nanocomposite. 

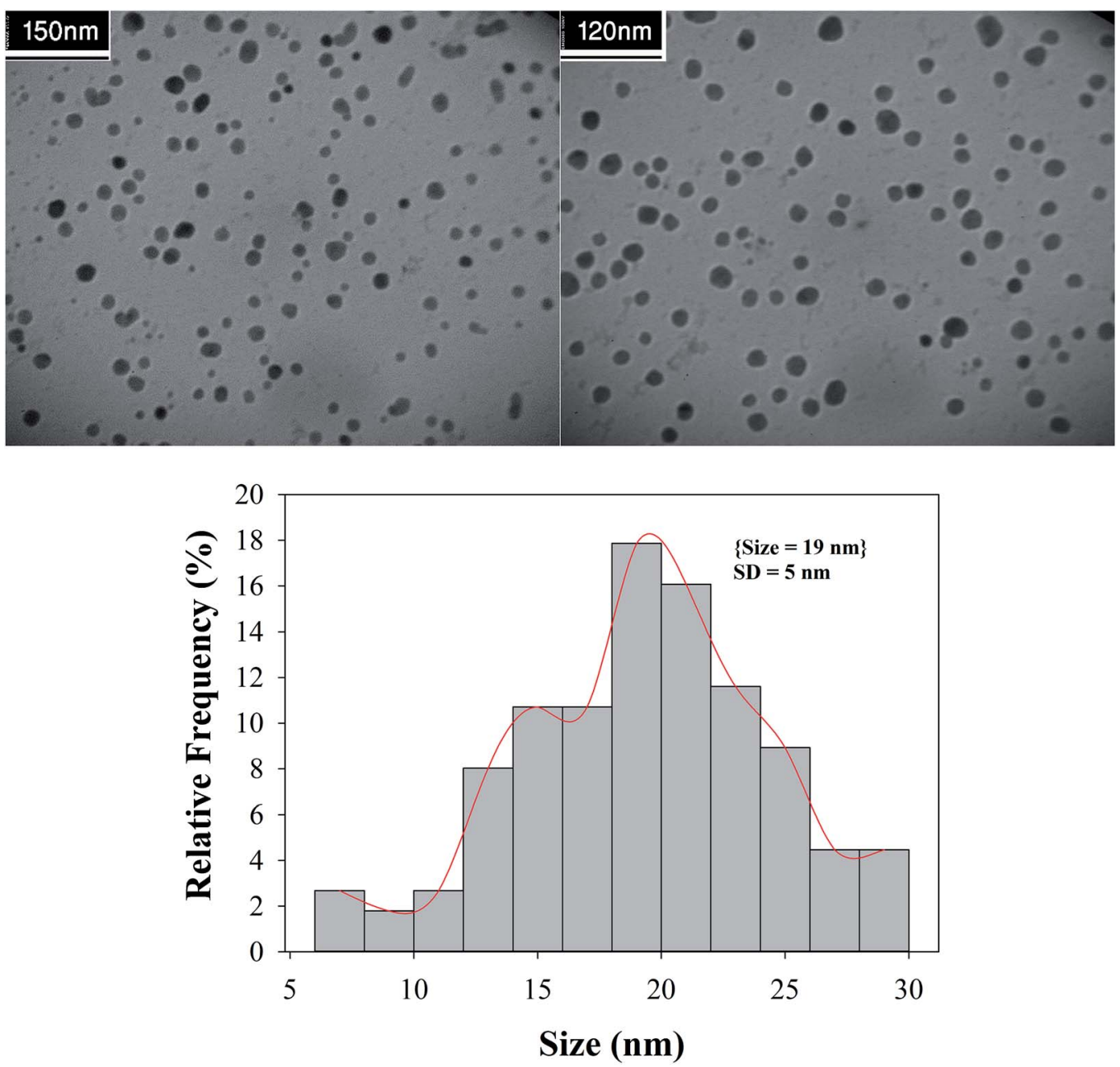

Fig. 8 TEM images and histogram of particle size distribution of the $\mathrm{Cu} / \mathrm{MgO}$ nanocomposite.<smiles>O=[N+]([O-])c1ccc(O)cc1</smiles><smiles>C[13CH2]c1ccc([N+](=O)[O-])cc1</smiles>
$\mathrm{Cu} / \mathrm{MgO}$ nanocomposite $\longrightarrow$

4-Nitrophenolate<smiles>Nc1ccc(O)cc1</smiles>

4-AP

Scheme 2 The catalytic reduction of 4-NP to 4-AP at room temperature.

Fig. 4 shows the X-ray diffraction pattern and TEM analysis of the $\mathrm{Cu}$ NPs. The patterns at $2 \theta$ values $43.7^{\circ}, 50.7^{\circ}$ and $74.5^{\circ}$ can be assigned to (1 111 ), ( $\left.\begin{array}{lll}2 & 0 & 0\end{array}\right)$ and ( $\left.\begin{array}{lll}2 & 2 & 0\end{array}\right)$ crystal planes in Cu cubic structure which agrees with the standard Cu (JCPDS 71-4610).

The biosynthesized $\mathrm{Cu}$ NPs structure and size was examined using TEM analysis. It is clear from Fig. 4 that the sizes of the $\mathrm{Cu}$ NPs are narrow, and the particles are mainly spherical in shape.

The stable $\mathrm{Cu} / \mathrm{MgO}$ nanocomposite obtained was fully characterized by UV-vis, FT-IR, TEM, SEM and EDS.

Fig. 5 shows the absorption spectrum of $\mathrm{Cu} / \mathrm{MgO}$ nanocomposite due to surface plasmon resonance (SPR) of metallic nanoparticles. At compare with spectra related to $\mathrm{Cu}$ NPs,

changing the color of the reaction (whitish to dark) and decrease the maxima ranging $500-580 \mathrm{~nm}$ indicates the reduction process and formation of nanoparticles. As monitored by UV-vis the synthesized nanoparticles by this method are quite stable with no significant variance in the shape, position and symmetry of the absorption peak even after 30 days which indicates the stability of product.

Furthermore, FT-IR spectrum of $\mathrm{Cu} / \mathrm{MgO}$ nanocomposite is shown in Fig. 5. The appeared bands are lattice vibration modes indicating the functional groups of sample. The bands below $1000 \mathrm{~cm}^{-1}$ are related to the $\mathrm{Mg}-\mathrm{O}$ absorption. A high absorption band, which appeared at $1610 \mathrm{~cm}^{-1}$, is also observed in the $\mathrm{MgO}$ spectrum, which is related to bending vibration of absorbed water and surface hydroxyl $(\mathrm{OH})$. The peak at $1485 \mathrm{~cm}^{-1}$ is assigned to the bending vibration of $\mathrm{OH}$ bond. The sharp absorption peak at $3697 \mathrm{~cm}^{-1}$ is due to the antisymmetric stretching vibration in the $\mathrm{Mg}(\mathrm{OH})_{2}$.

The morphology of the $\mathrm{Cu} / \mathrm{MgO}$ nanocomposite is revealed by FESEM. FESEM analysis (Fig. 6) of the $\mathrm{Cu} / \mathrm{MgO}$ nanocomposite prepared by Cassytha filiformis L. showed that copper particles deposited on the rough surface of $\mathrm{MgO}$ with flake- and sheet-shaped morphology. 


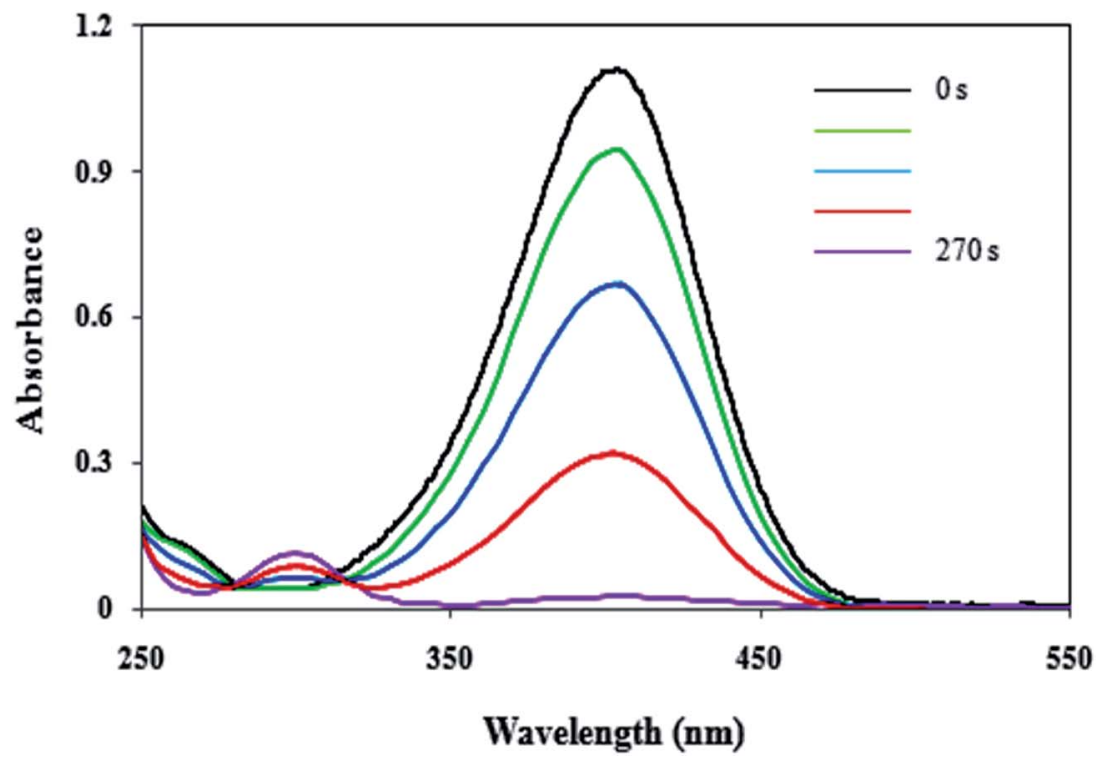

Fig. 9 UV-visible spectra of the 4-NP reduced by the $\mathrm{Cu} / \mathrm{MgO}$ nanocomposite. Reaction conditions: $10.0 \mathrm{mg}$ of $\mathrm{Cu} / \mathrm{MgO}$ nanocomposite, $25 \mathrm{~mL}$ of $4-\mathrm{NP}$ aqueous solution $(2.5 \mathrm{mM})$ and $25 \mathrm{~mL}$ of $\mathrm{NaBH}_{4}$ aqueous solution $(2.5 \mathrm{mM})$ at room temperature.

The elemental composition of the $\mathrm{Cu} / \mathrm{MgO}$ nanocomposite was determined by EDS analysis (Fig. 7). Presence of magnesium $(\mathrm{Mg})$, oxygen $(\mathrm{O})$ and copper $(\mathrm{Cu})$ was confirmed by EDS spectroscopy.

A close examination of the TEM images in Fig. 8 reveals that the nanoparticles are spherical morphology in shape. As may be seen in the TEM images, the average diameter of particles is $19 \mathrm{~nm}$.

\section{Catalytic ability of $\mathrm{Cu} / \mathrm{MgO}$ nanocomposite for reduction of 4-} NP, 2,4-DNPH, MB and CR

Catalytic ability and application of the synthesized $\mathrm{Cu} / \mathrm{MgO}$ nanocomposite investigated in the reduction of 2,4-DNPH, 4$\mathrm{NP}, \mathrm{CR}$ and MB. In the present method, the catalytic reduction of nitro compounds and organic dyes in the presence of $\mathrm{NaBH}_{4}$

Table 1 Completion time for the reduction 4-NP to 4-AP at room temperature using different amounts of $\mathrm{Cu} / \mathrm{MgO}$ nanocomposite

\begin{tabular}{llll}
\hline Entry & Catalyst $(\mathrm{mg})$ & $\begin{array}{l}\mathrm{NaBH}_{4} \\
\text { (equivalents) }\end{array}$ & $\begin{array}{l}\text { Time } \\
(\mathrm{min})\end{array}$ \\
\hline 1 & - & 100 & $140 \mathrm{~min}^{a}$ \\
2 & $\mathrm{MgO}(10.0)$ & 100 & $40 \mathrm{~min}^{b}$ \\
3 & $\mathrm{Cu} / \mathrm{MgO}$ nanocomposite $(7.0)$ & 0.0 & $300 \mathrm{~min}^{b}$ \\
4 & $\mathrm{Cu} / \mathrm{MgO}$ nanocomposite & 100 & $270 \mathrm{~s}$ \\
& $(10.0)$ & & \\
5 & $\mathrm{Cu} / \mathrm{MgO}$ nanocomposite $(7.0)$ & 100 & $280 \mathrm{~s}$ \\
6 & $\mathrm{Cu} / \mathrm{MgO}$ nanocomposite $(5.0)$ & 100 & $537 \mathrm{~s}$ \\
7 & $\mathrm{Cu} / \mathrm{MgO}$ nanocomposite & 79 & $477 \mathrm{~s}$ \\
& $(10.0)$ & & $10 \mathrm{~min}$ \\
8 & $\mathrm{Cu} / \mathrm{MgO}$ nanocomposite & 50 & $300 \mathrm{~min}^{b}$ \\
9 & $(10.0)$ & 0.0 & $520 \mathrm{~s}$ \\
10 & $\mathrm{Cu} \mathrm{NPs}$ & 100 &
\end{tabular}

${ }^{a}$ No reaction. ${ }^{b}$ Not completed. in water at room temperature was chosen as a pattern reaction to evaluate the catalytic activity of $\mathrm{Cu} / \mathrm{MgO}$ nanocomposite.

\section{Catalytic ability of $\mathrm{Cu} / \mathrm{MgO}$ nanocomposite for reduction of 4-} NP at room temperature

In present work, the catalytic activity of the $\mathrm{Cu} / \mathrm{MgO}$ nanocomposite was evaluated by the reduction of 4-NP as hazardous matter to 4-AP in the presence of $\mathrm{NaBH}_{4}$ as reducing agent in water (Scheme 2).

4-NP in aqueous medium has a maximum absorption at 317. After the addition of the $\mathrm{NaBH}_{4}$ solution, the new absorption peak at $400 \mathrm{~nm}$ is appeared due to formation of 4-nitrophenolate (Fig. 9). In the presence of $4-\mathrm{NP}+\mathrm{NaBH}_{4}$ solution and in the absence of $\mathrm{Cu} / \mathrm{MgO}$ nanocomposite does not happen any

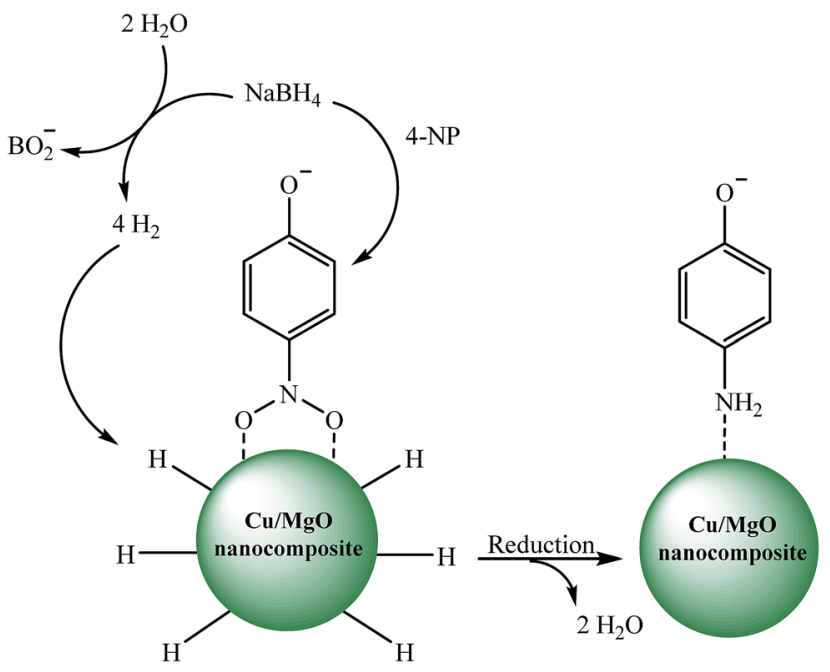

Scheme 3 Possible mechanism for the catalytic reduction of 4-NP to $4-\mathrm{AP}$ by $\mathrm{Cu} / \mathrm{MgO}$ nanocomposite at room temperature. 
<smiles>NNc1ccc([N+](=O)[O-])cc1[N+](=O)[O-]</smiles>

2,4-DNPH
2,4-DAPH

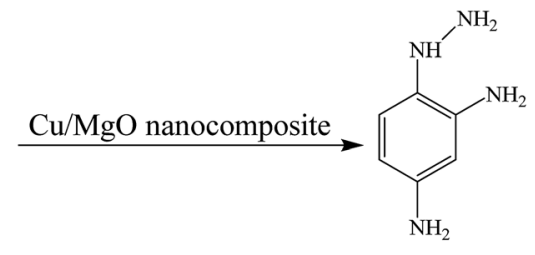

Scheme 4 The catalytic reduction of 2,4-DNPH to 2,4-DAPH in aqueous medium at room temperature.

Table 2 Completion time for the reduction 2,4-DNPH to 2,4-DAPH at room temperature using different amounts of $\mathrm{Cu} / \mathrm{MgO}$ nanocomposite and $\mathrm{NaBH}_{4}$

\begin{tabular}{|c|c|c|c|}
\hline Entry & Catalyst (mg) & $\begin{array}{l}\mathrm{NaBH}_{4} \\
\text { (equivalents) }\end{array}$ & Time \\
\hline 1 & - & 104 & $120 \min ^{a}$ \\
\hline 2 & $\mathrm{MgO}(10.0)$ & 104 & $7 \mathrm{~min}$ \\
\hline 3 & $\mathrm{Cu} / \mathrm{MgO}$ nanocomposite $(5.0)$ & 75 & $25 \min ^{b}$ \\
\hline 4 & $\mathrm{Cu} / \mathrm{MgO}$ nanocomposite (5.0) & 104 & $5 \min$ \\
\hline 5 & $\mathrm{Cu} / \mathrm{MgO}$ nanocomposite (7.0) & 104 & $220 \mathrm{~s}$ \\
\hline 6 & $\begin{array}{l}\mathrm{Cu} / \mathrm{MgO} \text { nanocomposite } \\
(10.0)\end{array}$ & 50 & $15 \min ^{b}$ \\
\hline 7 & $\begin{array}{l}\mathrm{Cu} / \mathrm{MgO} \text { nanocomposite } \\
(10.0)\end{array}$ & 75 & $15 \min ^{b}$ \\
\hline 8 & $\begin{array}{l}\mathrm{Cu} / \mathrm{MgO} \text { nanocomposite } \\
(10.0)\end{array}$ & 104 & $160 \mathrm{~s}$ \\
\hline
\end{tabular}

reduction process under alkaline conditions (Table 1, entry 1 ). As show in Fig. 9, after the addition of the $\mathrm{Cu} / \mathrm{MgO}$ nanocomposite to 4- $\mathrm{NP}+\mathrm{NaBH}_{4}$ solution, a new absorption signal at $300 \mathrm{~nm}$ is appeared following the formation of 4-AP and the solution color changes from yellow to colorless. We also investigated the effect of the amount of the $\mathrm{NaBH}_{4}$ for the reduction of 4-NP. In the absence of $\mathrm{NaBH}_{4}$, no reduction occurred within the reaction time (entry 3 and 9). The best result was obtained with $10.0 \mathrm{mg}$ of $\mathrm{Cu} / \mathrm{MgO}$ nanocomposite with 100 equivalents of $\mathrm{NaBH}_{4}$ (Table 1, entry 4). After completion of the reaction and conversion of 4-NP to 4-AP, the peak at $400 \mathrm{~nm}$ was disappeared. As shown in Table 1, the reaction took place after $520 \mathrm{~s}$ in the presence of $\mathrm{Cu}$ NPs. According the results, $\mathrm{Cu} / \mathrm{MgO}$ nanocomposite is much more reactive than Cu NPs and the reaction was completed during $270 \mathrm{~s}$ in the presence of the $\mathrm{Cu} / \mathrm{MgO}$ nanocomposite. The $\mathrm{MgO}$ is not only a support to prevent aggregation of the $\mathrm{Cu}$ NPs, but also can provide a synergistic effect in reduction process, which allow more molecules to be in contact with the surface of $\mathrm{Cu}$ NPs.

The reduction process of 4-NP to 4-AP is usually carried out in presence of a catalyst in aqueous media at room temperature. Therefore, presence of the $\mathrm{Cu} / \mathrm{MgO}$ nanocomposite as a catalyst and $\mathrm{NaBH}_{4}$ as a reducing agent is necessary for reduction of 4-NP. In the absence of the $\mathrm{Cu} / \mathrm{MgO}$ nanocomposite and $\mathrm{NaBH}_{4}$, reduction reaction did not proceed even after a long time (Table 1).

The catalytic reduction of the 4-NP by using $\mathrm{Cu} / \mathrm{MgO}$ nanocomposite is an electron transfer (ET) process. The reaction was carried out in two steps (Scheme 3). In the first step of process, 4-NP and $\mathrm{BH}_{4}$ diffuse from aqueous solution to the surface of catalyst via $\pi-\pi$ stacking interactions. In the next step, after electron transfer from the $\mathrm{BH}_{4}{ }^{-}$(reductant) and 4-NP (oxidant) near to the $\mathrm{Cu}$ NPs on the MgO surface as the electron mediator, the hydrogen atoms, which are formed from $\mathrm{BH}_{4}{ }^{-}$, attack 4-NP molecule to reduce it. Finally, the corresponding product was desorbed from the surface of the catalyst. These observations indicate that the $\mathrm{MgO}$ can stabilize the supported $\mathrm{Cu}$ NPs against aggregation also enhance the catalytic activity through a synergistic effect.

\section{Catalytic ability of $\mathrm{Cu} / \mathrm{MgO}$ nanocomposite for reduction of 2,4-DNPH at room temperature}

The catalytic reduction of 2,4-DNPH aqueous solution with $\mathrm{NaBH}_{4}$ at room temperature has also been used as another

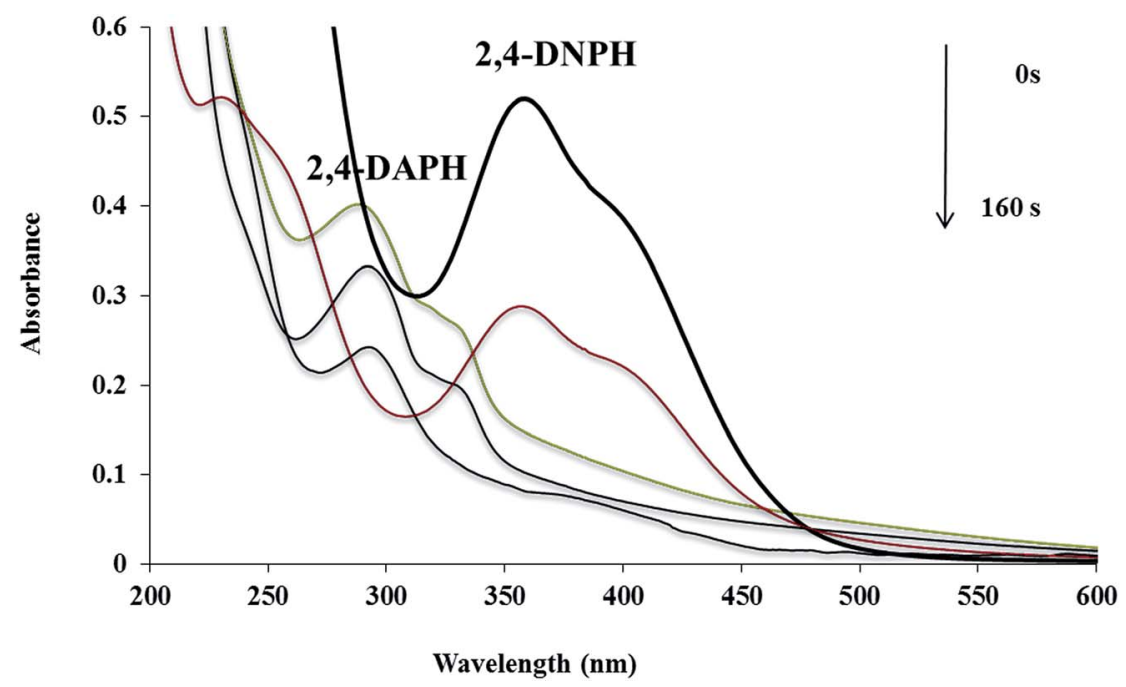

Fig. 10 UV-visible spectra of the 2,4-DNPH reduced by the $\mathrm{Cu} / \mathrm{MgO}$ nanocomposite. Reaction conditions: $10.0 \mathrm{mg}$ of Cu/MgO nanocomposite, $25 \mathrm{~mL}$ of 2,4-DNPH $(10.076 \mathrm{mM})$ and $25 \mathrm{~mL}$ of $\mathrm{NaBH}_{4}$ solution $(7.91 \mathrm{mM})$ at room temperature. 


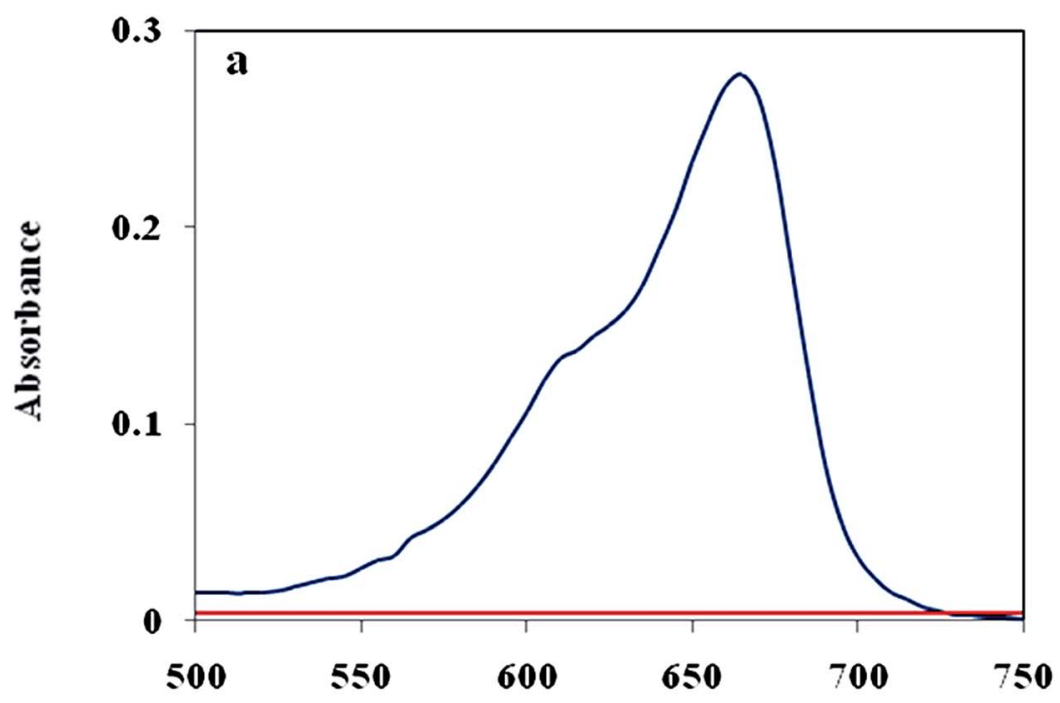

Wavelength (nm)

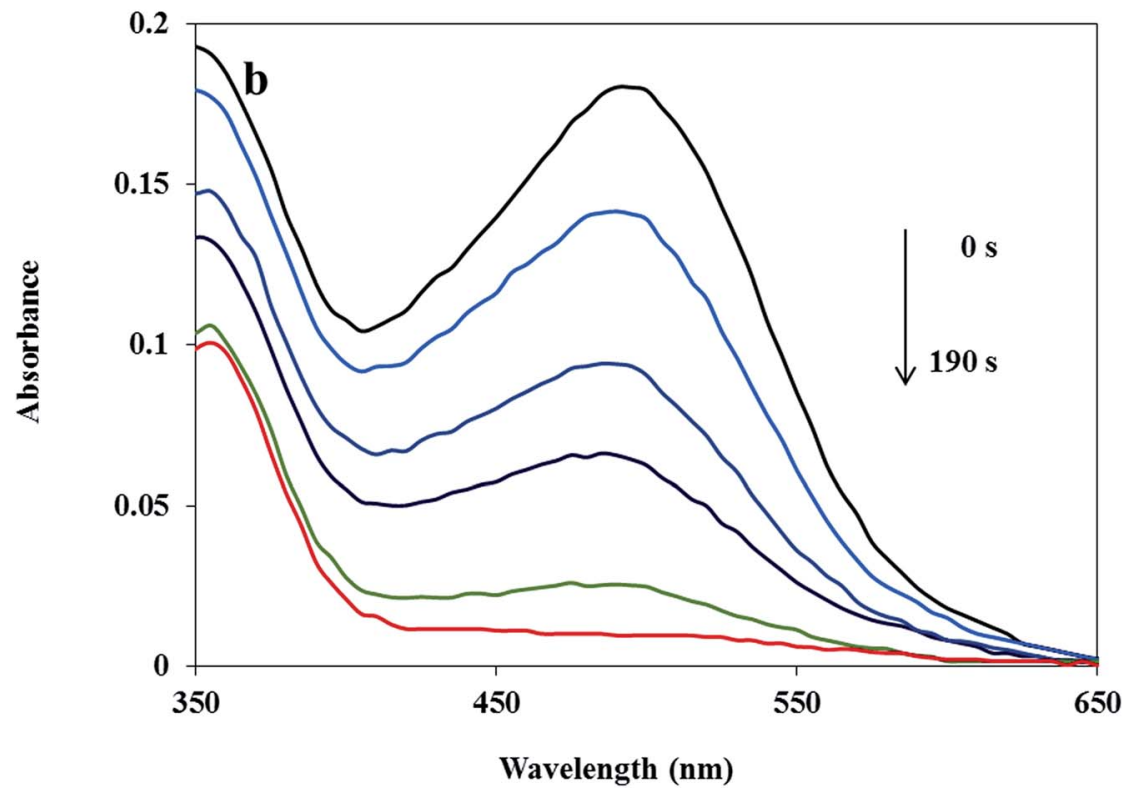

Fig. 11 UV-visible spectra of the MB (a) and CR (b) reduced by using $\mathrm{Cu} / \mathrm{MgO}$ nanocomposite at room temperature.

model reaction to check the catalytic activity of the $\mathrm{Cu} / \mathrm{MgO}$ nanocomposite (Scheme 4).

The $\mathrm{Cu} / \mathrm{MgO}$ nanocomposite demonstrated high activity for reduction of 2,4-DNPH to 2,4-DAPH in very short time (Table 2). This process was monitored by UV-vis spectroscopy. The 2,4$\mathrm{DNPH}$ in aqueous medium has a maximum absorption at $353 \mathrm{~nm}$ (Fig. 10). After the addition of $\mathrm{NaBH}_{4}$ to $2,4-\mathrm{DNPH}$ solution in the absence of the $\mathrm{Cu} / \mathrm{MgO}$ nanocomposite no change in the color of the solution and absorption spectrum was observed even after $120 \mathrm{~min}$ (Table 2, entry 1). After the addition of $\mathrm{Cu} / \mathrm{MgO}$ nanocomposite to the solution, a new absorption signal at $290 \mathrm{~nm}$ is appeared due to the formation of 2,4-DAPH. The effect of the concentration of $\mathrm{NaBH}_{4}$ and catalyst
Table 3 Optimization of reaction conditions for reduction of the MB and $C R$

\begin{tabular}{llll}
\hline Entry & Dye $(\mathrm{M})$ & Catalyst $(\mathrm{mg})$ & Time $(\mathrm{s})$ \\
\hline 1 & $\mathrm{MB}\left(3.1 \times 10^{-5}\right)$ & $\mathrm{Cu} / \mathrm{MgO}$ nanocomposite $(5.0)$ & 6 \\
2 & $\mathrm{MB}\left(3.1 \times 10^{-5}\right)$ & $\mathrm{Cu} / \mathrm{MgO}$ nanocomposite $(7.0)$ & 3 \\
3 & $\mathrm{MB}\left(3.1 \times 10^{-5}\right)$ & Cu/MgO nanocomposite & 1 \\
& & $(10.0)$ & 17 \\
4 & $\mathrm{MB}\left(3.1 \times 10^{-5}\right)$ & Cu NPs $(10.0)$ & 300 \\
5 & $\mathrm{CR}\left(1.44 \times 10^{-5}\right)$ & Cu/MgO nanocomposite $(5.0)$ & 300 \\
6 & $\mathrm{CR}\left(1.44 \times 10^{-5}\right)$ & Cu/MgO nanocomposite $(7.0)$ & 256 \\
7 & $\mathrm{CR}\left(1.44 \times 10^{-5}\right)$ & Cu/MgO nanocomposite & 190 \\
& & $(10.0)$ & 410
\end{tabular}


Table 4 Data for the catalytic reduction of 4-NP, 2,4-DNPH, CR and MB in presence of $\mathrm{NaBH}_{4}$ by different catalysts

\begin{tabular}{|c|c|c|c|c|c|}
\hline Substrate & Catalyst & Concentration (mL, mM) & $\mathrm{NaBH}_{4}(\mathrm{~mL}, \mathrm{mM})$ & Time (min) & Ref. \\
\hline \multirow[t]{5}{*}{ 4-NP } & Au@PZS@CNTs $\left(0.3 \mathrm{~mL}, 1 \mathrm{mg} \mathrm{mL}{ }^{-1}\right)$ & $1.7,0.2$ & $1.0,15.0$ & 16 & 40 \\
\hline & $\mathrm{Au}-\mathrm{GO}\left(0.25 \mathrm{~mL}, 1.4 \times 10^{-4} \mathrm{M}\right)$ & $10,0.750$ & $1.0,2.22 \times 10^{-3}$ & 7 & 41 \\
\hline & $\mathrm{Cu}$ microspheres $(0.5 \mathrm{mg})$ & $30.0,0.2$ & $10.0,25.0$ & 18 & 43 \\
\hline & Pd-FG $(1.0 \mathrm{mg})$ & $2.9,0.1$ & $0.1,10.0$ & 12 & 44 \\
\hline & $\mathrm{Cu} / \mathrm{MgO}$ nanocomposite $(10.0 \mathrm{mg})$ & $25,2.5$ & $25.0,250.0$ & 4 & This work \\
\hline \multirow[t]{2}{*}{ CR } & Cu@SBA-15 (1.0 mg) & $22.5,0.09$ & $5.0,200.0$ & 7 & 46 \\
\hline & $\mathrm{Cu} / \mathrm{MgO}$ nanocomposite $(10.0 \mathrm{mg})$ & $25.0,1.44 \times 10^{-2}$ & $25.0,5.3$ & $130 \mathrm{~s}$ & This work \\
\hline \multirow[t]{3}{*}{ MB } & $\mathrm{Au} @ \mathrm{TiO}_{2}(2.0 \mathrm{mg})$ & $20.0,0.04$ & $2.0,100.0$ & 12 & 47 \\
\hline & Natrolite zeolite/Pd (7.0 mg) & $25.0,0.03$ & $25.0,5.3$ & $1 \mathrm{~s}$ & 48 \\
\hline & $\mathrm{Cu} / \mathrm{MgO}$ nanocomposite $(10.0 \mathrm{mg})$ & $25.0,3.1 \times 10^{-2}$ & $25.0,5.3$ & $1 \mathrm{~s}$ & This work \\
\hline
\end{tabular}

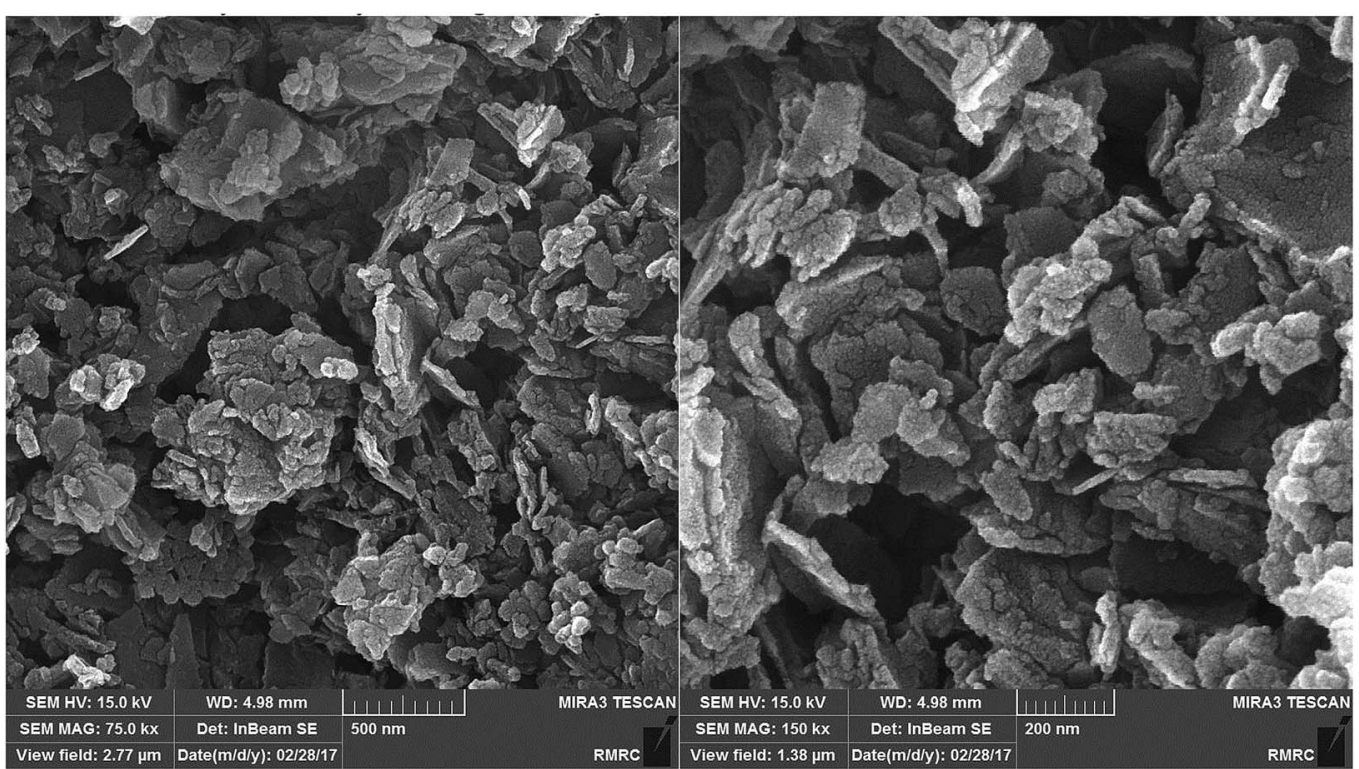

Fig. 12 FESEM images of recovered $\mathrm{Cu} / \mathrm{MgO}$ nanocomposite.

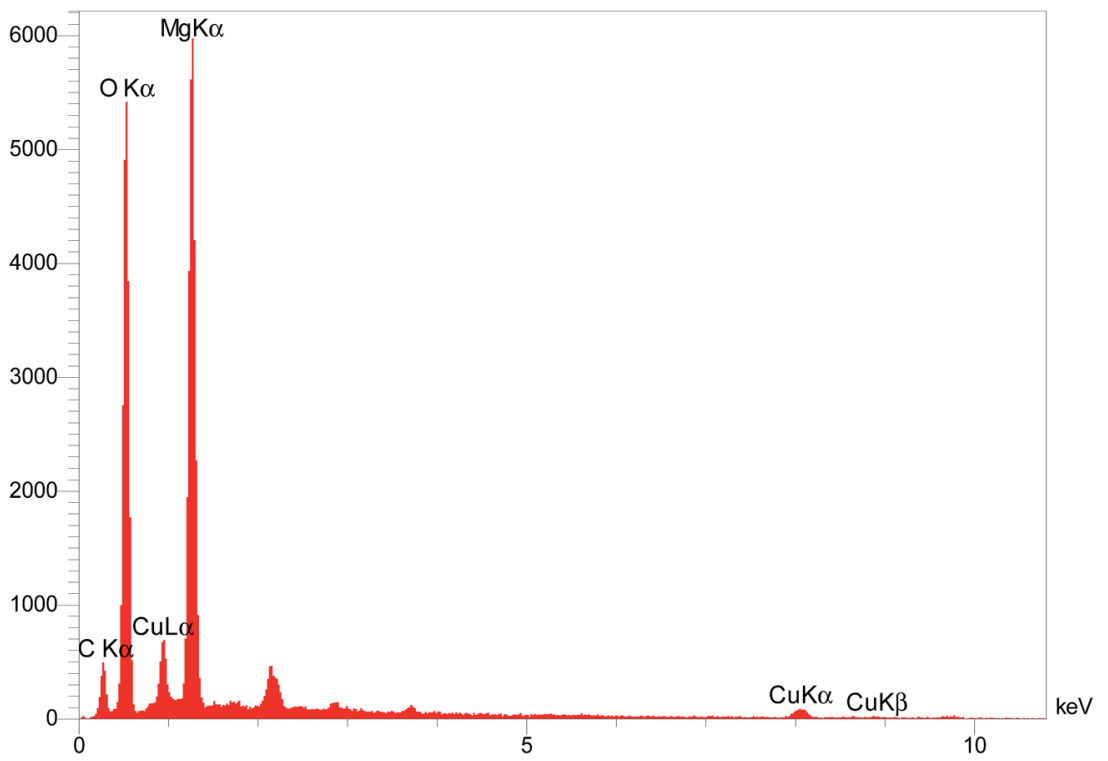

Fig. 13 EDS analysis of recovered $\mathrm{Cu} / \mathrm{MgO}$ nanocomposite. 


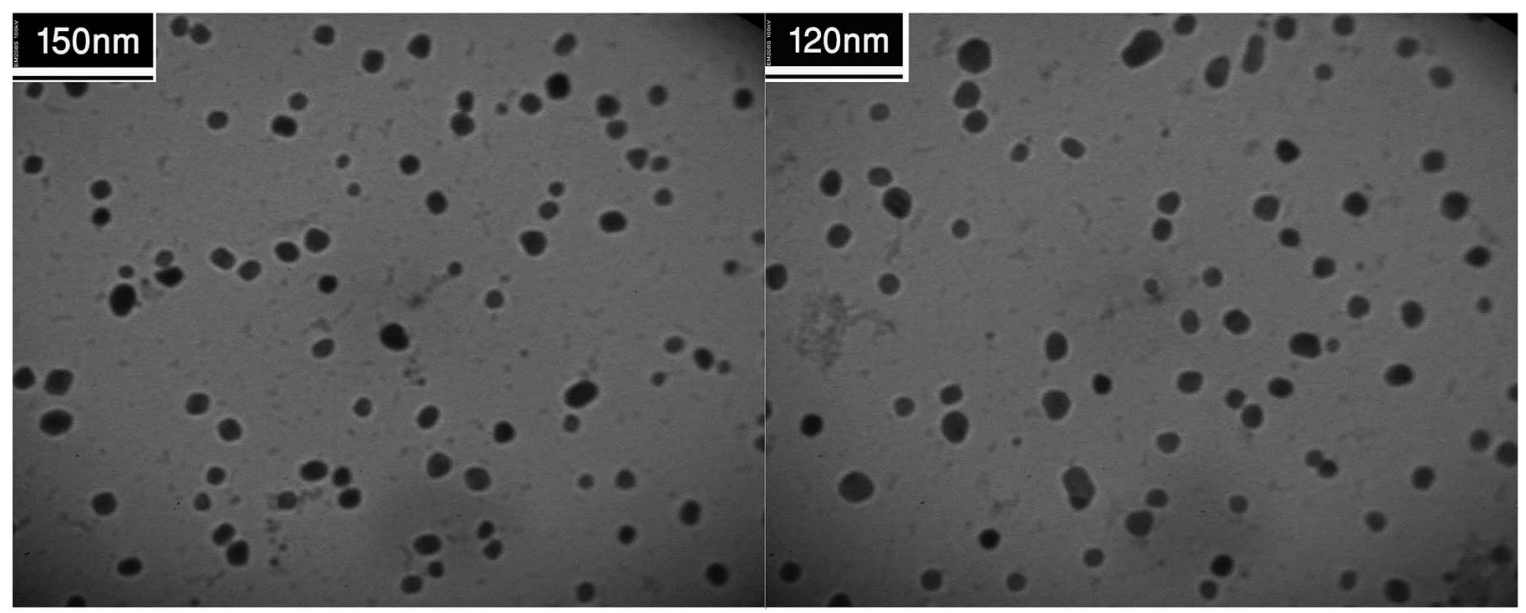

Fig. $14 \mathrm{TEM}$ images of recovered $\mathrm{Cu} / \mathrm{MgO}$ nanocomposite.

loading was studied by carrying out the reduction reaction in the presence of varying amounts of the $\mathrm{NaBH}_{4}$ and catalyst. In the absence of $\mathrm{NaBH}_{4}$, no reduction occurred within the reaction time. The best result was obtained with 104 equivalents of $\mathrm{NaBH}_{4}$ and $10.0 \mathrm{mg}$ of the $\mathrm{Cu} / \mathrm{MgO}$ nanocomposite (Table 2, entry 8 ).

\section{Catalytic ability of the $\mathrm{Cu} / \mathrm{MgO}$ nanocomposite for reduction of the MB and CR at room temperature}

In addition, the reduction of the $\mathrm{MB}$ and $\mathrm{CR}$ were chosen to evaluate the performance of the as-prepared $\mathrm{Cu} / \mathrm{MgO}$ nanocomposite. The catalytic reduction of $\mathrm{MB}$ and $\mathrm{CR}$ was investigated with $25 \mathrm{~mL}$ of fresh $\mathrm{NaBH}_{4}$ aqueous solution $\left(5.3 \times 10^{-3}\right.$ $\mathrm{M})$ and different amounts of catalyst at room temperature. The MB and CR dyes represented a characteristic SPR band at $\lambda_{\max }$ 663 and $493 \mathrm{~nm}$, respectively (Fig. 11). It is mentioned here that the no decolorization of dye could be detected in the absence of the $\mathrm{NaBH}_{4}$ or catalyst. The effect of the catalyst loading is a significant issue for the reduction of dyes. As shown in Table 3 , it was observed that reduction of MB and CR occurred within $1 \mathrm{~s}$ and $190 \mathrm{~s}$, respectively in the presence of $10.0 \mathrm{mg}$ of the $\mathrm{Cu} /$ $\mathrm{MgO}$ nanocomposite. The progress of the reaction was monitored using UV-visible measurements at ordered intervals of time. The catalytic activity of the prepared Cu NPs by Cassytha filiformis L. extract was also tested for the reduction of MB and CR (Table 3, entry 4 and 8). It is interesting to note that the $\mathrm{Cu}$ NPs gave poorer activity.

The catalytic activity of the prepared $\mathrm{Cu} / \mathrm{MgO}$ nanocomposite towards 2,4-DNPH, 4-NP, MB and CR reduction was compared with reported catalysts in the literature. According to Table 4, the $\mathrm{Cu} / \mathrm{MgO}$ nanocomposite exhibited a higher catalytic activity than other catalysts. As shown in Table 4, the best result was obtained with $\mathrm{Cu} / \mathrm{MgO}$ nanocomposite at room temperature with shorter reaction times. In addition, the $\mathrm{Cu} /$ $\mathrm{MgO}$ nanocomposite were synthesized by a green technique

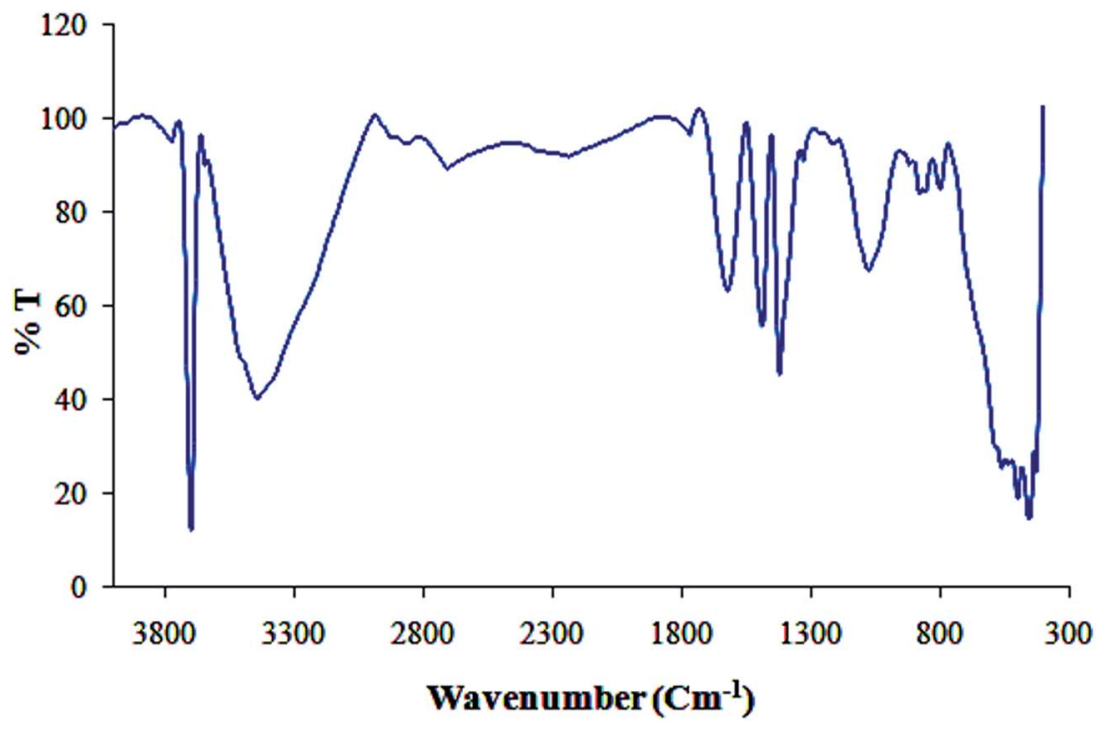

Fig. 15 FT-IR spectrum of recovered $\mathrm{Cu} / \mathrm{MgO}$ nanocomposite. 
using Cassytha filiformis L. extract without use of dangerous and toxic reagents or capping agent and surfactant.

\section{Catalyst recyclability}

The recyclability of the catalysts is one of the advantages of heterogeneous catalysts. The stability and reusability of the $\mathrm{Cu}$ / $\mathrm{MgO}$ nanocomposite was tested in the reduction of $\mathrm{CR}$ with $\mathrm{NaBH}_{4}$. The $\mathrm{Cu} / \mathrm{MgO}$ nanocomposite can be separated from the reaction mixture by mild centrifugation and washed with distilled water several times, dried and then reused at least six times without significant loss of catalytic activity. The high activity of catalyst confirms the high stability of $\mathrm{Cu} / \mathrm{MgO}$ nanocomposite under the reaction conditions. As shown in TEM, FESEM, FT-IR images and EDS analysis of the recycled catalyst (Fig. 12-15), no obvious change in structure, chemical composition, morphology and size of NPs were observed. The XRD patterns before and after the reaction revealed that the $\mathrm{Cu}$ / $\mathrm{MgO}$ nanocomposite retained its crystallinity throughout.

\section{Conclusion}

The green synthesis of copper nanoparticles using Cassytha filiformis L. extract provides a rapid and simple route for the preparation of $\mathrm{Cu} / \mathrm{MgO}$ nanocomposite. The flavonoids present in extract of Cassytha filiformis L. act as both reducing and capping/stabilizing agents. The synthesized $\mathrm{Cu}$ and $\mathrm{Cu} / \mathrm{MgO}$ nanocomposite were characterized by XRD, SEM, EDS, TEM, FT-IR and UV-vis spectroscopic techniques. The catalyst exhibits high catalytic activity for the reduction of 2,4-DNPH, 4$\mathrm{NP}, \mathrm{MB}$ and CR by using $\mathrm{NaBH}_{4}$ in aqueous medium at room temperature. The significant advantages of this methodology are elimination of hazardous materials, short reaction time, mild reaction conditions and simple work-up procedure.

\section{Conflicts of interest}

There are no conflicts to declare.

\section{Acknowledgements}

We gratefully acknowledge the Iranian Nano Council and the University of Qom for the support of this work.

\section{References}

1 R. Dai, J. Chen, J. Lin, S. Xia, S. Chen and Y. Deng, J. Hazard. Mater., 2009, 170, 141.

2 J. C. Spain, Annu. Rev. Microbiol., 1995, 49, 523.

3 F. Han, V. Kambala, M. Srinivasan, D. Rajarathnam and R. Naidu, Appl. Catal., A, 2009, 359, 25.

4 M. Nasrollahzadeh, M. Atarod, B. Jaleh and M. Gandomirouzbahani, Ceram. Int., 2016, 42, 8587.

5 V. Vidhu and D. Philip, Micron, 2014, 56, 54.

6 Y. Choi, H. S. Bae, E. Seo, S. Jang, K. H. Park and B.-S. Kim, J. Mater. Chem., 2011, 21, 15431.

7 Z. Xiong, L. L. Zhang, J. Ma and X. S. Zhao, Chem. Commun., 2010, 46, 6099.
8 M. Mansoob Khan, J. Lee and M. H. Cho, Ind. Eng. Chem. Res., 2014, 20, 1584.

9 N. Gupta, H. P. Singh and R. K. Sharma, J. Mol. Catal. A: Chem., 2011, 335, 248.

10 S. Li, H. Li, J. Liu, H. Zhang, Y. Yang, Z. Yang, L. Wang and B. Wang, Dalton Trans., 2015, 44, 9193.

11 K. B. Narayanan and H. H. Park, Korean J. Chem. Eng., 2015, 32, 1273.

12 Z. Wang, S. Zhai, J. Lv, H. Qi, W. Zheng, B. Zhai and Q. An, RSC Adv., 2015, 5, 74575.

13 H. R. Pouretedal, A. Norozi, M. H. Keshavarz and A. Semnani, J. Hazard. Mater., 2009, 162, 674.

14 C. Karunakaran, G. Abiramasundari, P. Gomathisankar, G. Manikandan and V. Anandi, J. Colloid Interface Sci., 2010, 352, 68.

15 B. K. Ghosh, S. Hazra, B. Naik and N. N. Ghosh, Powder Technol., 2015, 269, 371.

16 G. N. Panin, A. N. Baranov, Y. J. Oh and T. W. Kang, Curr. Appl. Phys., 2004, 4(6), 647.

17 G. N. Panin, A. N. Baranov, Y. J. Oh, T. W. Kang and T. W. Kim, J. Cryst. Growth, 2005, 279(3-4), 494.

18 H. S. Jung, J. K. Lee and M. Nastasi, Langmuir, 2005, 21(23), 10332.

19 T. Takada, Y. Hayase, Y. Tanaka and T. Okamoto, IEEE Trans. Dielectr. Electr. Insul., 2008, 15(1), 1070.

20 N. R. Dhineshbabu, G. Karunakaran, R. Suriyaprabha, P. Manivasakan and V. Rajendran, Nano-Micro Lett., 2014, 6(1), 46.

21 G. Khade, M. Suwarnkar, N. Gavade and K. Garadkar, J. Mater. Sci.: Mater. Electron., 2015, 26, 3309.

22 J. Choi, D. Reddy, M. Islam, B. Seo, S. Joo and T. Kim, Appl. Surf. Sci., 2015, 358, 159.

23 L. Z Fekri, M. Nikpassand and K. H Pour, Curr. Org. Synth., 2015, 12, 76.

24 Z. Issaabadi, M. Nasrollahzadeh and S. M. Sajadi, J. Cleaner Prod., 2017, 142, 3584.

25 A. R. Vartooni, M. Nasrollahzadeh and M. Alizadeh, J. Alloys Compd., 2016, 680, 309.

26 N. Muhd Julkapli and S. Bagheri, Rev. Inorg. Chem., 2016, 36, 1.

27 M. N. Nadagouda and R. S. Varm, Green Chem., 2008, 10, 859. 28 J. Y. Song and B. S. Kim, Bioprocess Biosyst. Eng., 2009, 32, 79. 29 H. Bar, D. K. Bhui, G. P. Sahoo, P. Sarkar, S. Pyne and A. Misra, Colloids Surf., A, 2009, 348, 212.

30 A. K. Mittal, Y. Chisti and U. C. Banerjee, Biotechnol. Adv., 2013, 31, 346.

31 M. Sathishkumar, K. Sneha, S. W. Won, C.-W. Cho, S. Kim and Y.-S. Yun, Colloids Surf., B, 2009, 73, 332.

32 M. Bordbar, RSC Adv., 2017, 7, 180.

33 M. Bordbar, Z. Sharifi-Zarchi and B. Khodadadi, J. Sol-Gel Sci. Technol., 2017, 81, 724.

34 T. P. T. Cushnie and A. J. Lamb, Int. J. Antimicrob. Agents, 2005, 26, 343.

35 L. M. Perry, Medicinal plants of east and southeast asia: attributed properties and uses, MIT Press, Cambridge, MA, 1980, p. 95. 
36 S. Mythili, S. Gajalakshmi, A. Sathiavelu and T. B. Sridharan, Asian J. Plant Sci. Res., 2011, 1, 77.

37 S. O. Ngele and J. O. Oti Wilberforce, Global J. Pharmacol., 2016, 10, 101.

38 C. Adonu Cyril, et al., Res. J. Pharm., Biol. Chem. Sci., 2013, 4, 1143.

39 M. Atarod, M. Nasrollahzadeh and S. M. Sajadi, RSC Adv., 2015, 5, 91532.

40 X. Wang, J. Fu, M. Wang, Y. Wang, Z. Chen, J. Zhang, J. Chen and Q. Xu, J. Mater. Sci., 2014, 49, 5056.

41 Y. Choi, H. S. Bae, E. Seo, S. Jang, K. H. Park and B.-S. Kim, J. Mater. Chem., 2011, 21, 15431.
42 Z. Jiang, J. Xie, D. Jiang, X. Wei and M. Chen, CrystEngComm, 2013, 15, 560.

43 Y. Zhang, P. Zhu, L. Chen, G. Li, F. Zhou, D. Lu, R. Sun, F. Zhou and C. P. Wong, J. Mater. Chem., 2014, 2, 11966.

44 Z. Wang, C. Xu, G. Gao and X. Li, RSC Adv., 2014, 4, 13644. 45 Th. Babita Devi, Md. Ahmaruzzaman and S. Begum, New J. Chem., 2016, 40, 1497.

46 B. K. Ghosh, S. Hazra, B. Nak and N. N. Ghosh, Powder Technol., 2015, 269, 371.

47 M. M. Khan, J. Lee and M. H. Cho, J. Ind. Eng. Chem., 2014, 20, 1584.

48 A. Hatamifard, M. Nasrollahzadeh and J. Lipkowski, RSC $A d v .$, 2015, 5, 91372. 